\title{
Eckhart: la condición humana y su camino de transformación hacia una existencia en Dios
}

\author{
JOSÉ S. TORRES MUÑOZ* \\ Universidad Santo Tomás (Colombia) \\ jostomu@yahoo.com \\ EDITH GONZÁLEZ BERNAL ** \\ Pontificia Universidad Javeriana (Colombia) \\ edith.gonzalez@javeriana.edu.co \\ NELSON R. MAFLA*** \\ Pontificia Universidad Javeriana (Colombia) \\ nelson.mafla@javeriana.edu.co
}

\begin{abstract}
Resumen
Para Eckhart la transformación del ser humano opera a partir de un progresivo reconocimiento que cada uno hace de su propia condición creatural a la luz de la vida intratrinitaria de Dios. El ser humano necesita liberarse de su constante inseguridad y dependencia de las cosas y de las convenciones sociales. Solo así puede iniciar ese camino de transformación que le permite ir de su condición terrenal, truncada por posesiones, miedos y limitaciones hacia una existencia en Dios plena en el espíritu, en la gratuidad y en la libertad. Este camino (theosis) conduce a la unión con Dios, pero ésta solo se alcanza a través del desasimiento de las cosas y del ego.

Palabras clave: Eckhart, condición humana, desasimiento (kénosis), unión con Dios (agápè).

\section{Eckhart: the human condition and its path of transformation towards an existence in God}

\begin{abstract}
For Eckhart the transformation of the human being operates from a progressive recognition that each one makes of his own creature condition in the light of God's intratrinitarian life. Human beings need to be freed from their constant insecurity and dependence on things and social conventions. Only in this way can he initiate that path of transformation which allows bim to go from bis earthly condition, truncated by possessions, fears and limitations to an existence in God full of the spirit, gratuitousness and freedom. This way (theosis) leads to union with God, but this is only achieved through the disengagement of things and ego.
\end{abstract}

Keywords: Eckhart, human condition, disengagement (kenosis), union with God (agápē).

* Doctor en educación, USTA Bogotá. Doctorem in Theologia, PUJ.

** Doctora en Teología Pontificia Universidad Javeriana. Doctora en Ciencias de la Educación, Universidad Pedagógica y Tecnológica de Colombia. Directora del grupo de investigación ACADEMIA de la Pontificia Universidad Javeriana, clasificación A 2017. *** Doctor en Ciencias de las Religiones, Universidad Complutense de Madrid (España).

Recibido: 1/Abril/2018 - Aceptado: 23/Julio/2018 


\section{INTRODUCCIÓN $^{1}$}

El pensamiento del Maestro Eckhart se caracteriza por la audacia para crear nuevas comprensiones del misterio humano y divino al conjugar en su reflexión el conocimiento bíblico, la teología trinitaria y fundamental y la espiritualidad mística. Su particular comprensión de la condición humana, alejada del espiritualismo y del moralismo de su época, lo lleva a descubrir en el ser humano a la creatura que tiene por vocación seguir el camino que conduce hacia Dios. Sin embargo, con buen criterio del conocedor del alma humana, Eckhart sabe que este camino hacia Dios no es ni fácil ni expedito. Requiere de un proceso de transformación, de conversión, de volverse a Dios para liberarse de las posesiones del ego que parte del reconocimiento de la propia condición creatural humana: "en efecto, en tanto el deseo 'de más y más' persiste en ti, Dios no puede habitar ni operar en ti" (Eckhart, 2002: 45). A este camino el Maestro lo llama 'desasimiento' (Gelassenheit) ${ }^{2}$ que en las categorías bíblicas correspondería a la kenosis. A esta continua liberación de las cosas y de sí mismo corresponde un movimiento de apertura, de recepción que conducen a la unión con Dios.

\section{ITINERARIO EN EL PENSAMIENTO ECKHARTIANO}

Eckhart propone una visión del ser humano radicalmente distinta de la que ofrece la tradición del pensamiento occidental o de la que tenemos hoy en día. Para este pensador medieval el ser humano es una creatura, un homo viator, cuya meta más elevada "es el nacimiento del Hijo en el alma, equivalente a la unión mística de lo humano y lo divino, alcanzable sólo mediante un proceso de purificación: una unión de voluntades y no de esencias, concedida por la gracia y no por el mérito" (Grinberg, 2002: 14).

En este sentido, el ser humano tiene siempre ante sí un camino existencial por el que puede convertirse en un ser de luz, despojándose de los convencionalismos y de la posesividad. Asimismo, el ser humano puede

1 Este artículo es producto de la investigación La condición humana, un camino de Kénosis en el Maestro Eckhart. Lectura bíblico-teológica. ID 00007002. Investigación financiada por la Pontificia Universidad Javeriana. La investigación se inscribe dentro del grupo de investigación ACADEMIA de la Pontificia Universidad Javeriana, clasificación A 2017.

2 Bara-Bancel: “transformación en el concepto de 'dejar'; se pasa de haberlo dejado todo (gelâzen hân), en el sentido de una renuncia activa de toda posesión, a tener un 'ser dejado', 'desprendido', 'entregado' o 'abandonado' (gelâzen sîn) - un ser tal que se pone en manos de Dios hasta el extremo de vaciarse de todo y permanecer inalterable en toda situación” (2015: 303-304). 
liberarse mediante un camino espiritual de crecimiento que le permita descubrir su vocación hacia la trascendencia. La visión antropológica de Eckhart enfatiza el camino de liberación que conduce a los seres humanos de una dependencia de las cosas hacia una libertad para Dios. La crítica que Eckhart hace de los mecanismos culturales, sociales, ideológicos e inconscientes que atan a todas las personas a su propia inseguridad, constituye una crítica válida a ciertos males característicos de nuestro tiempo: el consumismo, el activismo, el voluntarismo.

Pero, al intentar esta lectura debemos advertir no solo lo obvio, es decir la enorme distancia entre las preocupaciones del siglo XIV y las preocupaciones actuales, sino que debemos percatarnos de que su pensamiento gira de una manera sorprendente en torno a la interpretación bíblica. En efecto, cada uno de los sermones tiene como punto de partida y como estructura discursiva algún pasaje particular de la Biblia (Davies, 1994). De modo que al leer a Eckhart se debe advertir de inmediato que si bien él utilizó la lengua común de su época, todas sus referencias coinciden con las categorías del pensamiento bíblico, en especial las de la teología paulina y las de las Cartas Católicas. Algunos comentaristas muestran que en Eckhart se produjo una síntesis entre la escolástica, la mística y el pensamiento bíblico (Sturlese, 2014).

Junto a esto también se reconoce el constante interés que su pensamiento suscita, no solo en el ámbito religioso o teológico de su época, sino en todo el pensamiento del siglo XX. Su forma radical de ver la humanidad a la luz de su experiencia de fe cuestiona profundamente los supuestos que tenemos sobre la manera como nos relacionamos con las realidades que consideramos sustantivas en la vida humana, como las posesiones, la riqueza o el bienestar.

A esto se debe también añadir el uso particular que Eckhart hace de la 'lengua vernácula' para sus predicaciones y que es objeto de estudios y de precisiones en las introducciones a su obra alemana. Como señala Grinberg:

Eckhart se propuso no quedar confinado en el marco de los académicos: pensaba que las verdades más hondas de la religión, e inclusive las vivencias más sublimes de la vida religiosa debían ser puestas al alcance de la gente común. Por eso se concentró en predicar y en escribir en alemán, aun sobre temáticas muy complejas. (2002: 20)

Sturlese que ha hecho una edición bilingüe de una parte de las prédicas, advierte que Eckhart recurre a un procedimiento, bien conocido en la retórica clásica y bíblica, llamado locutio emphatica: 
[...] el modus loquendi emphaticus es, según el texto eckhartiano, propio de la Escritura, de los santos y de los predicadores y tiene la capacidad de suscitar emociones (la lágrima) y la obtiene a través de fórmulas comprensivas sintéticas y particularmente eficaces a las que subyacen, una irresistible explicación de tipo argumentativo-racional [...]. (Sturlese, 2014: xxxix)

Aunque estas características de hermenéutica teológica, de adaptación persuasiva al auditorio y de uso innovador y magistral de la lengua no entran directamente en el estudio de las categorías de este breve estudio, es útil conocerlas para poder encuadrar adecuadamente las constantes novedades y la creatividad de este autor a la hora de comunicar al común de la gente las novedades de la espiritualidad mística.

Con esto señalamos ahora algunos elementos centrales en el análisis del pensamiento eckhartiano trasmitido en su obra alemana, en particular lo que se refiere a la condición humana, es decir, al lugar del ser humano creyente en la historia de la revelación.

$\mathrm{Al}$ emprender este breve estudio, centrado en las consideraciones que Eckhart hace sobre la condición humana, hemos puesto los ojos en lo que se llama "la obra alemana", es decir, un conjunto de textos destinados a la predicación popular, escritos en la lengua corriente de la época ${ }^{3}$. Nos parece que allí aparecen las preguntas vitales que hacen inteligible en profundidad la inteligencia con la que se comprende su planteamiento antropológico. Respecto al valor de esta parte de la obra de Eckhart, nos dice Fromm "su mayor influencia proviene de sus sermones en alemán, que influyeron no sólo en sus contemporáneos y en sus discípulos, sino también en los místicos alemanes posteriores y, hoy día, en los que buscan una guía auténtica" (1978: 69).

En esta lectura hemos considerado algunos elementos que se reiteran en la antropología teológica de Eckhart como son el continuo llamado al 'desasimiento' y la perenne búsqueda de la 'unión con Dios' (Vannier, 2012). De hecho, nos hemos planteado explícitamente la pregunta por la lectura bíblica y teológica que el Maestro Eckhart hace sobre la condición humana y sobre el desasimiento (kénosis) como camino para llegar a la unión con Dios (agápè).

En esta búsqueda se ha detectado que en su pensamiento el ser humano aparece en una constante tensión entre lo interior y lo exterior, entre la seguridad que supone el poseer y la libertad que exige el ser, entre las

3 Grinberg: Eckhart "sin cesar refinaba el idioma alemán, acuñando términos originales y recurriendo a hipérboles, conglomerados de palabras que apuntan a darle mucho énfasis a un sentimiento a una idea específica. De ese modo, el orador, y el Maestro Eckhart era de los mejores, se aparta conscientemente del sentido literal de algunas palabras y de la construcción convencional de las frases" (2002: 20). 
exigencias de coherencia formal y la autenticidad de la incertidumbre. En todo ello, sin embargo, prima el criterio de sentirse a gusto, de comprender el momento y comprenderse a sí mismo en ese momento: "quien está bien encaminado en medio de la verdad, se siente a gusto en todos los lugares y con todas las personas" (Eckhart, 1983: 68).

El itinerario que aquí se propone, toma como eje de la reflexión una meditación sobre el "ser humano noble" en la cual Eckhart plantea explícitamente su antropología del 'bomo viator', el ser humano que sale de sí mismo, recibe un reino y retorna. Antes de abordar el análisis de la obra de Eckhart haremos algunas consideraciones metódicas y conceptuales respecto a la «condición humana» como categoría de análisis, relacionándola con los conceptos de desasimiento y de unión con Dios.

El concepto que exploramos en la obra alemana de Eckhart y que de hecho se convierte en la categoría central es su concepción del ser humano. En el caso de Eckhart resulta fundamental relacionar su visión antropológica con su concepción fuertemente trinitaria de Dios y con la confrontación continua entre lo que él considera auténticamente espiritual que difiere con frecuencia de las prácticas piadosas de su época: el reconocimiento de la propia condición creatural humana, el desasimiento y la unión con Dios. Por ello, preferimos hablar más de condición humana que de naturaleza humana. La condición humana se refiere al modo como la naturaleza humana interactúa con las formas culturales del pensamiento y con la manera como cada ser humano se experimenta a sí mismo, mientras la naturaleza humana se liga a ciertas características universales de la especie humana.

La categoría "condición humana" engloba el núcleo de una antropología que incluye todos los datos conocidos sobre al ser humano, desde el dato biológico hasta la determinación económica, sin descartar lo que cada época y cada cultura aportan en la comprensión de lo que el ser humano en cuanto individuo y especie ha sido, es y será.

Esta categoría está conformada por un sintagma de dos palabras que enuncian un conjunto de situaciones, determinaciones, circunstancias y estructuras que explicitan lo que el ser humano ha llegado a ser en el devenir de la historia y que lo diferencian decididamente de otras creaturas. Para entender esto se explicitan a continuación algunas nociones y definiciones que configuran esta categoría.

En primer lugar, en la misma palabra "condición" confluyen dos significados que le vienen del latín (Soto Posada, 2007). Por una parte, "condición" se refiere a la palabra compuesta por el prefijo "con-" que indica movimiento conjunto o simultaneidad y un derivado verbal del verbo " $d i$ cere", de amplio uso en latín y en castellano, que significa 'decir, indicar, 
mostrar, exponer'. En la composición del prefijo y el derivado verbal tenemos, entonces, que condición significa un conjunto de características que una realidad exhibe como propias o inherentes y que en castellano sería el equivalente del verbo "condecir" (lat. condecère). La otra posibilidad, está en el latín tardío, en la que se relaciona con el significado de 'asentar, fundar, especificar' (lat. conditǐo, -ōnis). De modo que la condición se convierte en una característica inherente sobre la cual se asienta una determinada realidad, bien sea en el plano natural, social o sobrenatural. De ahí la expresión latina 'conditio sine que non'.

En segundo lugar, el adjetivo 'humano' indica que el contenido de la condición se refiere a aquello que nos constituye como especie frente a los otros seres vivos y frente a las cosas. Lo humano en su etimología (lat. bumānus) se refiere al suelo, a la tierra fértil, al humus del que el ser humano ha surgido y que en la Biblia ha sido tematizado en los relatos de Génesis (Gn 1, 1-2, 26) y en otros géneros (Sal 8, 1ss).

Al sumar estas dos posibilidades encontramos que la condición le viene dada a una realidad desde una determinación, de modo que esa realidad no se puede dar o prescindir de esas determinaciones internalizadas. Es el caso, en particular, del ser humano que desde el primer momento se halla en estado total de indefensión física ante la naturaleza y ante otros, pero tiene una enorme potencialidad cognitiva, situación única en el ámbito natural. Esa es su condición natural, es decir, la condición misma como el ser humano se manifiesta como individuo y como especie.

\section{LA NOBLEZA HUMANA}

La meditación sobre el 'hombre noble' que aparece en el Liber Benedictus, con la que ahora se comienza, tiene la ventaja de exponer algunos datos fundamentales de la antropología teológica de este Gran Maestro. En particular, su capacidad de presentir ciertas tendencias de la historia humana contemporánea, en especial las que se refieren al hedonismo, la codicia y el consumismo que desequilibran las relaciones que el ser humano tiene consigo mismo, con los otros, con la naturaleza y, por supuesto, con la divinidad. En palabras de Fromm, el gran riesgo que corre la humanidad si la condición humana radica en la dinámica de la posesión y no en la dinámica del ser: "el Maestro Eckhart enseñó que no tener nada y permanecer abierto y «vacío», no permitir al ego ser un estorbo en nuestro camino, es la condición para lograr salud y fuerza espiritual" (1978: 33).

La reflexión de un pasaje del evangelio de Lucas $(\operatorname{Lc} 9,12)$ sirve de motivo inicial para desarrollar una reflexión antropológica "sobre el hombre noble" (Von dem edein menschen). Ahora bien, para Eckhart una reflexión 
antropológica tiene que ser teológica, es decir, debe conducir a una comprensión del ser humano en su orientación fundamental hacia Dios (theosis).

A partir del pasaje en cuestión (Lc19,12: ergo homo quidam nobilis abiit in regionem longinquam accipere sibi regnum et reverti), Eckhart realiza una lectura simbólica de tres elementos: el ser humano cuya vocación lo hace noble (bomo nobilis) ${ }^{4}$ el itinerario de ida (abeo) y vuelta (revertor) y la recompensa de esa peregrinación que es el reino (regnum). De acuerdo con esto, el ser humano es noble en su origen creatural, gracioso en su itinerario espiritual y divino en su destino.

En primer lugar, el punto de partida lo constituye la realidad creatural del ser humano que es, ante todo, raíz y fundamento de su vocación divina. La creatura ha sido formada por el creador a partir del humus (Gn 2, 7). Al igual que el resto de la creación, el ser creatural humano tendería de suyo a Dios, pero, ahí está lo particular, en cuanto que es imagen y semejanza del Creador debe poner en juego su libertad que le permitiría o bien encaminarse o bien distraerse para realizar su camino, itinerario o destino.

La tensión que se produce, siguiendo la terminología paulina, en la lucha entre el ser humano nuevo y el ser humano viejo, el nuevo y el antiguo Adán (Rm 5,14; 1 Co 15, 22. 45). Esta tensión se comprende mejor si se considera que, por una parte el ser humano aunque es noble en su origen por ser imagen y semejanza de su creador (Gn 1,27: et creavit Deus bominem ad imaginem suam), debe depurar esa imagen a través de un vaciamiento o kénosis y, por otra, si se considera que existe una tensión entre el ser humano viejo, conformado según criterios mundanos y el ser humano nuevo, redimido en el Hijo.

Esta realidad supone una tensión y un desafío para la creatura humana en su itinerario hacia Dios. Por una parte, la tensión de su naturaleza que, si bien se puede abrir hacia lo trascendente, se ve igualmente atraída hacia la mundanidad. Por otra parte, sin embargo, el ser humano tiene el desafío de aceptar en libertad la verdad creatural, es decir, la humildad, su ser mortal, terrenal y sometido al tiempo.

La tensión creatural es presentada mediante la metáfora de la contraposición del hombre interior con el hombre exterior que corresponden a dos modos de estar en el mundo, pues como señala Haas, para Eckhart, como también antes que él, para toda una tradición platónica, estoica y, después, paulina y patrística, la tipología del hombre interior y exterior

\footnotetext{
$4 \quad \mathrm{Al}$ analizar la obra latina aparece la misma temática en el comentario de Eckhart al evangelio de Juan: "Uomo giusto, uomo nobile, non è altro che colui che si spoglia completamente di tutto se stesso, in quanto soggetto psicológico accidentalmente determinato: occorre abnegare personale, abnegare propium" (Vannini, 2009: 11).
} 
desempeña un papel constitutivo para su concepción del ser humano" (Haas, 2002). En el hombre interior prevalece el ser, la condición humana ligada a la realización de las potencialidades inherentes a ese estar en el mundo con otros iguales como parte íntegra de una creación. En contrapartida, está el hombre exterior en el que prevalece la posesión, el tener, condición humana ligada a la producción, al lucro y a la ganancia material, en la que todo se mira según la cantidad o la utilidad. La duplicidad entre lo exterior y lo interior humano constituyen el origen de una tensión ligada a su condición de creatura, de ser en el mundo. La resolución de esta tensión implica que el ser humano decida en libertad orientar toda su potencialidad hacia valores trascendentes que lo habrán de conducir a una unidad definitiva en Dios, o en declinar tal oferta.

Eckhart caracteriza la exterioridad humana como algo viejo, mundano, exterior, hostil y servil. No porque la inserción en la realidad física, biótica o social sea algo malo, sino porque se hace de un modo tal que se busca en toda la satisfacción del placer de poseer, incluso si lo que se busca es la aprobación del medio social o el prestigio producto del elogio.

Por el contrario, la interioridad humana se caracteriza por el auténtico conocimiento que comienza por el conocimiento del ser en la propia interioridad, lo que en la historia del pensamiento se ha tematizado como conocimiento de sí mismo: "Quien se conoce a sí mismo, conoce a todas las criaturas" (Eckhart, 1983: 219). De hecho, la alusión que Eckhart hace al pensamiento paulino acentúa cómo las personas a pesar del envejecimiento y del deterioro físico se van fortaleciendo en su ser interior que "se renueva día a día" (2 Co 4,16$)$.

Eckhart presenta la intensidad de esta tensión en su aspecto moral por medio de las figuras de ángeles y demonios en lucha constante, como lo ilustran las constantes alusiones paulinas a la lucha espiritual $(\mathrm{Rm} 7,23$; Gal 5,$17 ; 6,8)$. En ella la capacidad de decisión se ve sometida a una constante criba de motivaciones genuinas que ayude a discernir lo que realmente hay de valioso, original y bueno en el ser de cada persona. Por ello la imagen de ser interior se presenta mediante la imagen del árbol que produce buenos frutos (Mt 7,17) y por el campesino diligente que cuida de su campo (Lc 8, 11ss); el cultivo del ser interior, su formación como ser humano nuevo habilitan para ser partícipes de la realidad divina (2 Pe 1, 4). En contraposición, el hombre exterior aparece simbolizado por el árbol malo (Mt 7,18) o por el enemigo que siembra cizaña (Mt 13,24). Puesto que no hay aquí una dicotomía determinista, Eckhart insiste en que si la semilla es buena supera las condiciones adversas: "como Dios mismo sembró y colocó y engendró esta semilla, si bien es posible que sea cubierta y escondida, nunca podrá ser exterminada ni ahogada en sí misma" (1983: 222). 
En segundo lugar aparece el itinerario espiritual de la gracia: un éxodo y un retorno que tienen como meta la recepción de un reino (regnum). Se realiza en un ascenso de seis grados que sigue el modelo paulino de la maduración espiritual y el de la mística de la imagen divina. La mistagogía ayuda a comprender que en el despojo de la propia imagen se forma la imagen divina.

Este camino de realización espiritual que propone la segunda meditación del Liber benedictus, recuerda la escala de Jacob (Gn 28,11-19). Implica, ante todo, el despojo (desasimiento o kénosis) de la propia imagen, de modo que se pase progresivamente en un primer grado de la total de dependencia y certidumbre, a una plena configuración con Dios en el Hijo, en el sexto grado ( Gal 2,20). Desde el punto de vista psicológico, exige un proceso de maduración mediante la continua formación para que la persona se libere del sentido infantil de la aprobación o la dependencia. Desde el punto de vista espiritual, que corre paralelo al anterior, la persona crece en el amor universal (agápē; charitas), la sabiduría y la donación de sí mismo. Eckhart presenta este camino como una transición del amor materno protector al amor paterno, industrioso y creativo.

En el primer grado el ser humano noble depende de los buenos ejemplos de los demás y de la capacidad de aceptarlos y asimilarlos. En el camino de maduración se pasa de una etapa de dependencia a una realización plena (1 Co 3, 1ss; Hb 6, 1). En la terminología de Pablo, el ser humano nuevo aún se alimenta de leche porque aunque actúa bien necesita de un soporte explícito y externo (1Co 3,2).

El segundo grado se caracteriza por la iniciativa, porque sin prescindir del apoyo externo la persona creyente se encamina por su propia cuenta hacia Dios. Es una etapa de aprendizaje en la que se busca el consejo y la sabiduría de Dios.

El tercer grado implica una ampliación de la independencia y la superación del miedo mediante una relación amorosa con Dios. A partir de este punto los grados sucesivos son de crecimiento en ese amor de profunda raíz: el ser humano nuevo "está relacionado con Dios mediante el amor" (Eckhart, 1983: 223). Con ello se pasa de la dependencia a la acción amorosa recíproca.

El cuarto grado se podría identificar con la virtud de la resiliencia, pues se afrontan de buen ánimo los trabajos y los sacrificios. Se crece "cada vez más, enraizándose en el amor" y se aceptan con alegría las tribulaciones inherentes a este proceso de crecimiento.

El quinto grado se identifica con la paz consigo mismo y con la abundancia de sabiduría.

El sexto y último grado alcanza la plena configuración con la imagen divina, lo que supone desnudarse de la imagen previa y transformarse de 
acuerdo a la imagen del auténtico hijo de Dios. "la meta final del hombre interior y del hombre nuevo es: la vida eterna" (Eckhart, 1983: 224). Este es el ideal de la formación humanista que configura la imagen de la creatura de acuerdo a las infinitas posibilidades de la imagen divina: "el resurgimiento de la palabra «formación» despierta más bien la antigua tradición mística según la cual el ser humano lleva en su alma la imagen de Dios conforme la cual fue creado, y debe reconstruirla en sî́" (Gadamer, 1993: 39). Gadamer vincula la tradición humanística a este ideal según el cual el ser humano tiene en su existencia la tarea de hacerse más humano a través de su formación ${ }^{5}$.

En tercer lugar, aparece el destino humano, articulado a su itinerario y origen. Este destino es la unidad en lo divino. El ser humano se comprendería plenamente a partir de su unidad fundamental en Dios y la falta de ella produciría cierto enajenamiento o mundanización: "allí donde ello [es decir, lo Uno] no permanece dentro de sí, allí recibe, posee y produce diferencia” (Eckhart, 1983: 227).

El ser humano noble interior ha sido formado según la imagen de Dios y de Él ha recibido su semilla. La repristinización de esa imagen divina se consigue mediante el vaciamiento del propio pozo para que la fuente mane nuevamente, como el pozo de Jacob (Gn 26,18; Jn 4,6). La nobleza de origen no exime al ser humano del compromiso de depurar el devenir de su ser, pues, en el fondo de cada ser humano nuevo "están impresas y sembradas la semilla y la imagen de Dios" (Eckhart, 1983: 224). Los símbolos agrícolas acentúan la necesidad para el ser humano de cultivo o formación. Los símbolos familiares ilustran el proceso de maturación desde la dependencia materna hasta la libertad paterna.

La alusión a Jacob cuando libera el manantial de un pozo profundo sacando la tierra que lo ha bloqueado (Gn 26, 14), del sol que brilla oculto entre las nubes, del ojo opaco que percibe defectuosamente la luz, del escultor que saca la estatua del bloque de material, hacen "referencia al hombre noble y de cómo la imagen de Dios, el Hijo de Dios, la semilla de naturaleza divina dentro de nosotros, nunca es extirpada aun cuando se la encubre" (Eckhart, 1983: 226).

La tensión de la doble naturaleza se mantiene a lo largo del itinerario progresivo hacia Dios y su superación depende del juego de maduración entre la libertad y la voluntad: "el hombre debe dejar atrás todas las imágenes y a sí mismo y llegar a estar muy apartado y ser diferente de todas

5 La palabra formación (Bildung) tiene "su origen en la mística medieval, su pervivencia en la mística del barroco, su espiritualización fundada religiosamente" (Gadamer, 1993: 38). 
estas cosas, si realmente quiere y debe recibir al Hijo y hacerse hijo en el seno y corazón del Padre" (Eckhart, 1983: 226).

En otras palabras, la nobleza de la creaturalidad permite que el ser humano nuevo mantenga una tensión unitiva hacia su creador. La creaturalidad humana no solo le coloca en el orden físico o natural (biótico), sino que le ubica en el orden cultural e histórico en el que acontece la salvación. Respecto a su origen en el sexto día, su realidad como creatura última no elimina la humildad o verdad de su origen, ni la tensión de esa doble naturaleza creatural ni la libertad que lo libera o lo somete: "el hombre noble toma y saca su ser, su vida y su felicidad enteras exclusivamente de Dios, junto a Dios y en Dios" (Eckhart, 1983: 230-231).

Finalmente, se puede percibir como en la teología de Eckhart aparece claramente que la palabra latina homo y su equivalente griego ánthropos (ä $\vee \theta \varrho \pi \circ \varsigma)$, se refiere a cualquier ser humano -varón o mujer- en su condición de inserción en el mundo y de apertura hacia Dios. Las acciones referidas a este ser humano tienen en la Biblia y en Eckhart un carácter que pasa por la salida y el retorno. En la salida se ubica tanto la posibilidad de trascender como la de extraviarse. Para el retorno se utiliza en latín la palabra 'retorno' (Lc 19, 12: reverti) relacionada con la conversión, entendida como 'vuelta a Dios' del ser humano (2Pe 3,9: poenitentiam reverti). En esta predicación Eckhart señala la 'nobleza' (nobilis; engenés) creatural que da origen al ser humano, su destino divino y su camino de libertad:

Porque el hombre tiene que ser uno solo en sí mismo, buscando tal [estado] en su fuero íntimo y en lo Uno y recibiéndolo dentro de lo Uno, esto quiere decir: contemplar únicamente a Dios, y «volven» quiere decir: saber y conocer el hecho de que uno conoce a Dios y sabe [de Él]. (Eckhart, 1983: 232)

Eckhart, siguiendo las enseñanzas paulinas, representa al ser humano en una permanente tensión entre el aspecto exterior y el interior. El aspecto exterior se refiere a la manifestación funcional del ser humano, su inmersión en la vida social, su mundanidad. El interior se refiere a la apertura, volcamiento o salida hacia Dios. El ser humano en su interioridad es el nuevo Adam, llamado a la redención, pero en su interioridad es un ser viejo, mundano y hostil a la gracia. Por ello, de acuerdo al pensamiento eckhartiano el ser humano se cierra en su exteriorización al influjo mundano -la mundanidad diría Francisco- pero se abre en su interiorización a la acción de Dios, entendida como camino del Hijo hacia el Padre.

La temática de la diferencia es introducida positivamente cuando se indica que en la medida que el ser humano se convierte, al liberarse de las imágenes engañosas de las cosas y de sí mismo, en esa medida recibe al Padre en el Hijo, es decir se une con Dios (Eckhart, 1983: 224-225). Por 
el contrario, la imagen se vuelve opaca cuando la creatura no supera esa tensión para unirse a su Creador y ser uno en el Uno (1 Co 13,12).

La temática de la imagen desnuda de Dios evoca tanto la purificación de las motivaciones humanas del creyente como la memoria del crucificado que entrega su vida luego de su expoliación: "aquellos que llegan a conocer al Dios desnudo, conocen a la vez junto con Él a todas las criaturas" (Eckhart, 1983: 228); y además "lo primero en que reside la bienaventuranza es el hecho de que el alma contemple a Dios desnudo" (Eckhart, 1983: 228). Asimismo, el objeto del conocimiento o, incluso, el conocimiento mismo, conducen a la visión del Dios desnudo: "el conocimiento tiene la llave y abre y penetra y atraviesa y encuentra a Dios en su desnudez" (Eckhart, 1983: 284).

\section{QUID PRODEST, LA GANANCIA ESPIRITUAL}

El sermón Intravit Iesus in templum (Mt 21,12), considera tres elementos: el templo, los mercaderes y la acción de expulsión o vaciamiento. En la interpretación de Eckhart el templo representa el Espíritu humano, necesitado de vaciamiento (kénosis), para dejarse habitar por Dios; los mercaderes, ya sean cambistas o vendedores de palomas, representan las mentalidades de muchos creyentes que con buenas intenciones intentan o negociar con Dios (do ut des) o hacer algo bueno a cambio de una buena recompensa. El vaciamiento representa un proceso de expulsión de toda clase de intenciones que no coinciden con la realidad de Dios en la existencia humana. Estos tres elementos convergen en la donación inconmensurable de Dios que transforma la condición previa del ser humano, sujeto a preocupaciones de pérdida o ganancia, en una nueva condición en la que la vida espiritual se manifiesta en una plena participación en la comunicación divina.

Respecto al templo, Eckhart presenta una paradoja que consiste en vaciar para llenar. En la interpretación simbólica que Eckhart da a este pasaje, el templo representa el alma que necesita ser desocupada de todo comercio o pretensión de intercambio para que Dios pueda habitarla: "si Jesús ha de hablar en el alma, ella tiene que estar a solas y se debe callar ella misma si es que ha de escuchar" (Eckhart, 1983: 264).

La actitud con los mercaderes se enfrenta según la paradoja de no negociar para poder recibir. Los mercaderes representan a las personas que se contentan con un buen funcionamiento en el mundo y a todos aquellos que esperan una recompensa por hacer el bien; junto a estos están los vendedores de palomas que representan a ciertas personas buenas: 
[...] que hacen sus obras exclusivamente por amor de Dios y no buscan en ellas nada de lo suyo, pero las hacen con apego al propio yo, al tiempo y al número, al antes y al después. Esas obras les impiden la verdad óptima es decir, que deberían ser libres y desasidos tal como Nuestro Señor Jesucristo es libre y desasido. (Eckhart, 1983: 262-263).

Eckhart pone en cuestión la tendencia, ahora considerada normal, de someter todas las actividades de la vida humana al comercio, al intercambio mutuamente favorable. Sin embargo, para Eckhart esta lógica es irracional en el campo espiritual porque lo que se pretende es precisamente lo contrario, es decir, se debe renunciar a todo tipo de negociaciones con Dios para someterse a un proceso de vaciamiento (kénosis), representado en el gesto de la expulsión de mercaderes y vendedores de palomas del templo.

Buscar alguna cosa, un intercambio mutuamente favorable, incluso buscarse a sí mismo entre las cosas conduce, tarde o temprano, a un bloqueo frente a lo que Dios nos ha dado: la libertad.

[...] el hombre que no piensa en sí mismo ni en ninguna otra cosa sino sólo en Dios y en su honra, este hombre es libre y desasido del mercantilismo en todas sus obras y no busca lo suyo, así como Dios es libre y desasido en todas sus obras y no busca lo suyo. (Eckhart, 1983: 262)

\section{EL CONOCIMIENTO ES LA CLAVE}

El ser humano es imagen de Dios en el orden creatural. Esto supone una condición y un constante reconocimiento que le permita percibir su lugar en este orden y, al mismo tiempo, una exigencia constante de formación, cultivo y configuración que repristine esa imagen. Esa condición de creatura, con otras creaturas, y de imagen de Dios, requiere del ser humano que en su libertad se deje configurar con el Hijo hasta unirse por medio del Espíritu a la potencia del Padre. El ser humano, entonces, accede a esa unidad con su creador por la vía del conocimiento que reposa en su alma, pero que pasa por el desasimiento para alcanzar su unidad con el Uno.

Para Eckhart el conocimiento es unión con Dios "conocimiento y entendimiento unen al alma con Dios" (Eckhart, 1983: 282). Esto se relaciona, ante todo, con el conocimiento verdadero que viene de Dios y que Eckhart lo relaciona con el episodio de Pedro en la prisión, narrado en el libro de Hechos (Hch 12,11), en el que Pedro reconoce la intervención liberadora de Dios por medio de un ángel.

Por una parte, el conocimiento se refiere a la relación que tiene el Hijo con el Padre en las formulas ternarias del Nuevo Testamento (Mt 11,27) 
que identifican al Padre con la potencia, al Hijo con la igualdad, y al Espíritu con la unidad. Para Eckhart el verdadero conocimiento es una luz que viene de Dios, capaz de revelar la realidad de las cosas y de comunicar lo eterno en medio de lo mudable.

Por otra parte, el conocimiento es entendido desde el punto de vista sapiencial como participación real del alma en la realidad de las cosas. Pero no es que el alma se dirija hacia las cosas, sino que en su retorno hacia Dios, el alma supera la enajenación de las cosas. "nada ajeno puede caer en Dios" (Eckhart, 1983: 286).

El conocimiento se convierte por vía intratrinitaria o por puro discernimiento sapiencial en un itinerario del alma hacia Dios de quien recibe toda su forma: "Como Dios transforma en sí cosas tan insignificantes ¿qué os parece que hará con el alma distinguida por Él como su imagen?” (Eckhart, 1983: 286).

La consecuencia de este conocimiento es el despojo de la propia voluntad y el acogimiento de la voluntad de Dios: "aun cuando no tengas ni recogimiento ni fervor, ninguno de los dos, y lo que tengas o no tengas: disponte sin embargo a tener bien presente en todas las cosas la gloria de Dios y luego, cualquier cosa que te haga, será la mejor" (Eckhart, 1983: 288). Queda, entonces, el problema del discernimiento de la voluntad de Dios que no se identifica con un asunto concreto, sino con la satisfacción y la serenidad de encontrar en el amor a Dios el punto de soporte de toda la existencia: "Si amarais a Dios, nada podría resultaros más placentero que aquello que a Él le gustara ante todo y que su voluntad se hiciera en nosotros más que nada.” (Eckhart, 1983: 289-290). La insistencia contenida en la tercera petición del Padrenuestro, "hágase tu voluntad", constituye la esencia de aquello que se busca al hacer que la santificación del nombre de Dios, la venida de su reino y la realización de la voluntad se conviertan en el eje de toda acción.

En este sentido, los dones que vienen de Dios y el amor a Dios, al prójimo y a sí mismo tienen sentido en la medida en que proceden de Dios, constituyen una experiencia iluminadora de Dios y permiten el retorno a Dios. Los dones, por ejemplo, son más significativos cuanto más grandes y gratuitos son. No dependen de un mérito del individuo, sino únicamente del ser de Dios. Lo mismo el amor que no se mediría por grados de afecto o gestos de servicio, sino por su capacidad de ser una experiencia abarcante, universal: "Cuanto más nobles son las cosas, tanto más abarcadoras y universales son. El amor es noble por ser universal" (Eckhart, 1983: 291). Aunque formalmente el amor universal aparezca como un mandato, tiene el poder de reconstituir la realidad: "el amor antes que mandamiento es recompensa. El mandamiento parece difícil, la recompensa es apetecible" (Eckhart, 1983: 292). 
Los dones que proceden de Dios constituyen una donación y un don. Por ello, acentúan la gratuidad divina y la creaturalidad humana. Dios da, porque el darse constituye su ser y es lo que lo hace ser tal al engendrar su máximo don que es el Hijo; hijo que continúa dándose en el Espíritu, porque este es el ser de Dios. En este esquema, lo que le corresponde al ser humano es esa apertura al don de Dios que hace posible tal donación y que no la niega ni la acapara ni la elimina. El mayor don que Dios otorga es la generación darse como Padre en el Hijo y esa generación ocurre, según Eckhart, en el alma humana:

El Padre engendra a su Hijo en el conocimiento eterno, y exactamente de la misma manera el Padre engendra a su Hijo en el alma como en su propia naturaleza y lo engendra para que pertenezca al alma, y su ser depende de que — gústele o no—engendre a su Hijo en el alma. (Eckhart, 1983: 294)

Para Eckhart el hecho que el texto bíblico indique clara y específicamente que estos dones proceden de lo alto y descienden (St 1, 17: desursum est descendens) ayuda a comprender también su recepción: "a quien no se halla completamente abajo, nada le cae en suerte y tampoco recibe nada por insignificante que sea" (Eckhart, 1983: 295). La condición humana radica en el reconocimiento de la propia verdad, de la humilde realidad creatura, digna de todo y, sin embargo, sin mérito alguno.

La alusión a la expresión "Padre de las luces" $($ St 1,17$)$ hace referencia a esta manera sobrenatural que tiene Dios de darse en los seres, es decir, por medio de una luz universal que se relaciona con el entendimiento y el conocimiento (Eckhart, 1983: 294).

En otras palabras, en el pensamiento de Eckhart se puede detectar la búsqueda de una verdad existencial que reside en reconocerse como creatura ante el Creador, como hijo en el Hijo ante el Padre, como un humano lleno de sí que requiere del continuo desasimiento para alcanzar la unión con Dios, esta es la verdadera condición del ser humano abierto a Dios desde su interioridad.

\section{LA CONDICIÓN ADOPTADA Y ENALTECIDA}

Eckhart muestra que la teología trinitaria evidencia la gran dignidad que el ser humano recibe al ser adoptado por Dios Padre por medio de la filiación y, al mismo tiempo, la trasformación de esa realidad por el enaltecimiento que en el Hijo alcanza el ser humano en el orden celestial. El Sermón V (In hoc apparuit) habla de la adopción de la naturaleza humana por el Hijo (Eckhart, 2009: 250), es decir, la condición humana asumida y redimida por Jesucristo (Eckhart, 1983: 297). 
La interpretación de Jn 4, 9 se articula en etapas. La primera se refiere al enaltecimiento de la realidad humana en la realidad del Hijo. La segunda al envío del Hijo al mundo como manifestación del amor de Dios. La tercera a la donación de la vida en el gesto amoroso de envío del Hijo por parte del Padre. La cuarta, consecuencia de la anterior, a la manifestación de la condición humana en la manera como debemos acoger a Dios.

La primera etapa destaca la singularidad del ser humano al ser colocado en un lugart destacado en el orden total, formado por la creación terrenal y el orden celestial. La clave para comprender esta osada comprensión de la condición humana radica en la transformación que ha operado el Padre al adoptar al ser humano como un hijo en su Hijo. El don de Dios no consiste en dar alguna cosa singular, sino en darse completamente a sí mismo en lo más preciado que es su Hijo: "Todo cuanto, en algún momento, le dio a Él en [su] naturaleza humana, no me resulta ni más extraño ni más distante que a Él. Pues Dios no puede dar poca cosa; tiene que dar todo o nada" (Eckhart, 1983: 298). Esa donación exige reciprocidad en las relaciones interhumanas:

$[\ldots]$ es necesario que tú te encuentres en unión con los hombres de manera equidistante, no más cerca de ti mismo que de otra persona. Has de amar y estimar y considerar a todos los hombres como iguales a ti mismo; lo que sucede a otro, sea malo o bueno, debe ser para ti como si te sucediera a ti mismo. (Eckhart, 1983: 299)

El enaltecimiento opera de Dios Padre hacia la humanidad por medio de su Hijo y entre los seres humanos por medio de la consideración en el trato mutuo.

La segunda etapa indica que el envío del Hijo al mundo ocurre por el amor más allá de toda medida del Padre hacia las creaturas que constituyen su imagen y semejanza. El amor con el que cada ser humano ama a Dios en su prójimo y a su prójimo en Dios es un acto que se convierte en vía directa de comunión santificante, de divinificación o teosis: "Suena extraño que el hombre de tal manera puede llegar a ser dios en el amor; sin embargo, es verdad dentro de la verdad eterna. Nuestro Señor Jesucristo poseía esta [unión]" (Eckhart, 1983: 299). El mundo al que el Hijo es enviado no significa primordialmente algo malo, sino que es el punto de convergencia donde las creaturas pueden reconocer que son parte de algo más grande, de la realidad total que está en la acción creadora de Dios. En este sentido, el amor redime a la creatura, terrenal o angélica, de su propia carencia, de su falta de reconocimiento hacia la unidad total de la que proviene. 
La tercera etapa, la vida en Dios (1 Jn 4, 9: ut vivamus per eum), es una invitación para asumir la vida como motor de la existencia "¿Qué es mi vida? Lo que, desde dentro es movido por sí mismo" (Eckhart, 1983: 300). Esta manera de entender la vida exige que, por una parte, cooperemos en la acción de Dios desde una motivación interior, intrínseca a la acción misma. De modo que la recompensa sea la acción misma y no un resultado exterior o colateral. Por otra parte, exige que superemos la enajenación ante el orden creado y lo asumamos como propio, de modo que todas las cosas nos pertenezcan: "Él nos pertenece completamente y en Él todas las cosas nos pertenecen" (Eckhart, 1983: 301). La cooperación y la apropiación del orden creado conllevan a una simetría entre la realidad interior exterior e interior por lo que se supera la mera aprensión de los objetos o la heteronomía.

La cuarta etapa toma la enseñanza del pasaje bíblico y la conduce a una comprensión de la relación con Dios que, si bien tiene un punto de partida devocional y, por lo tanto, parcial, lleva a comprenderla como una realidad total: "Debéis pensar puramente en Dios y buscarlo a Él. Cualquiera que sea luego el modo resultante, jcontentaos con él! Pues vuestra intención ha de estar dirigida puramente hacia Dios y a ninguna otra cosa" (Eckhart, 1983: 302). La comprensión de un punto de partida integral y no parcial radica en que se entienda y asuma la condición humana, sometida a la tensión entre lo interior y lo exterior, entre lo parcial y lo total, entre lo que se retiene y lo que se puede llegar a ser: "tomad lo que Dios os quiere dar en ese momento y conservad siempre un humilde aniquilamiento y el rebajamiento" (Eckhart, 1983: 302). La captación esencial de su propio ser pasa para el ser humano por el reconocimiento de su origen terrenal, humilde, ligado a la creaturidad.

\section{QUERER, SABER Y TENER}

Una de las enseñanzas más desconcertantes de Meister Eckhart sobre la condición humana se refiere a la gratuidad, absoluta, al desasimiento y a la pura nada. Esta temática atraviesa toda su obra (Sauer, 1273), pero aparece de manera más específica en el Sermón LII (Mt 5, 3: Beati pauperes spiritu). Esta enseñanza se relaciona claramente con el tercer capítulo del Liber Benedictus que trata sobre el desasimiento (abegescheidenheit). En esta enseñanza Eckhart muestra el profundo impacto que tiene la ambición de poseer sobre la condición humana, en particular sobre la voluntad, la inteligencia y la acción.

La paradoja de esta enseñanza radica en el no tener nada, es decir, en reconocer el origen humilde, terrenal, adámico del ser humano. Eckhart 
es consciente de que esta situación puede afectar al ser humano bien porque ha sido depauperado (pobreza exterior) y que se refleja en una condición socioeconómica; o bien porque ha aceptado la indigencia humana necesitada de la solidaridad de Dios (pobreza interior) que se hace realidad en el desasimiento o vaciamiento (kénosis): "pobre es quien que no quiere nada y no sabe nada y no tiene nada" (Eckhart, 1983: 685).

Como siempre, Eckhart resuelve cualquier polaridad en la tensión creativa de estas dos maneras de entender la pobreza: la exterior y puramente mundana que se refiere a la privación de los medios de sustento o la interior y espiritual que se refiere a un crecimiento de Dios en el alma humana o crecimiento interior del ser.

Para Eckhart el postulado básico de la vida espiritual consisten en reconocer que el ser humano no puede tener, ni retener, ni contener nada. Por ello, aceptar la nada da paso al ser uno con Dios. Igualmente, permite la unidad total, la desaparición de la soledad o del sentimiento existencial de separación.

Sin embargo, en la búsqueda de ese desasimiento, de ese abandono de las cosas el creyente se enfrenta a unas fuerzas poderosas que viene del temor, de las convenciones sociales o, incluso, de ciertas ideas religiosas. La búsqueda existencial fácilmente es reemplazada por la búsqueda de posesiones, de la ambición de un prestigio social, del miedo ante lo incierto Las fuerzas que conspiran contra la posibilidad de liberarse giran en torno a los verbos, querer, saber, tener. La posesión de objetos, de vínculos extraordinarios y de personas conjura, al menos temporalmente, la angustia que sufren las personas cuando se consideran despojados, carentes o indignas. Especialmente esto último que ya era un problema complicado en la época de Eckhart se ha convertido en el eje de la cultura actual bajo la forma de consumo.

Eckhart distingue diversas formas de pobreza (Lavaud, 2012). La primera e indiscutible es la pobreza social y económica. Esta es una realidad básica que se puede asumir dentro de un camino espiritual. Luego están otras formas de ascética, mortificación y penitencia que asumen rasgos externos de austeridad pero que no son realmente "pobreza en el espíritu" según la sabiduría de las Bienaventuranzas (Mt 5, 3).

La primera característica de la persona realmente pobre es que prescinde del deseo, del querer, "no quiere nada". Pero, Eckhart introduce varias restricciones para que su comprensión no se identifique llanamente con la manera corriente de pensar o con prácticas religiosas de perfección individual.

Ante todo excluye de esta comprensión de la pobreza a las personas que bien sea por una severa austeridad o por ejercicio devocional se despojan de alguna posesión, pero siguen aferrados "a su propio yo en sus 
penitencias y ejercicios exteriores" (Eckhart, 1983: 685). En seguida, excluye a quienes pretenden colocar la voluntad de Dios por encima de los deseos individuales, sin embargo para Eckhart aún aquí subsiste un voluntarismo que no se supera sino con la absoluta renuncia a los propios anhelos, deseos y aspiración. Incluso a los más piadosos. "si el hombre de veras ha de poseer [la] pobreza, debe estar tan libre de su voluntad creada como lo era antes de ser" (Eckhart, 1983: 686).

La segunda característica es la persona que no sabe y que, por tanto, "ha de mantenerse tan libre de su propio saber, como [lo] hacía cuando no era, y que deje obrar a Dios lo que Él quiera, y que el hombre se mantenga libre" (Eckhart, 1983: 688). El conocimiento y el amor se condensan en una experiencia de Dios que supera la pretensión de sabiduría y que se abandona totalmente en el ser de Dios: "quien ha de ser, pues, pobre en espíritu, debe ser pobre en cuanto a todo su saber propio, de modo que no sepa nada de nada, ni de Dios ni de la criatura ni de sí mismo" (Eckhart, 1983: 689).

La tercera característica es la de la persona que no tiene nada. También en esta característica hay una gradualidad porque primero aparece la supresión de toda posesión y de todo deseo o certeza de poseer. El segundo grado, loable pero incompleto, es la liberación de todas las obras y cosas para dar lugar a Dios. El tercero y más extremo es el de una pobreza tal que no se tiene ni siquiera este lugar, sino que la pobreza en el espíritu consiste en "que [el hombre] se mantenga tan libre de Dios y de todas sus obras que Dios, si quiere obrar en el alma, sea Él mismo el lugar en el cual quiere obrar... y esto lo hace gustosamente" (Eckhart, 1983: 690).

Esta progresión conduciría en el pensamiento de Eckhart, en su theosis, hacia el mismo ser de Dios. El ser del ser humano podría, entonces, percibir como ha estado siempre en Dios y como en esa extrema pobreza a la que hace alusión este maestro, "Allá, Dios no halla lugar alguno en el hombre porque el hombre consigue con esta pobreza lo que ha sido eternamente y seguirá siendo por siempre jamás. Allá, Dios es uno con el Espíritu, y ésta es la pobreza extrema que se pueda hallar" (Eckhart, 1983: 693).

La condición humana de humildad, terrenalidad y precariedad alcanza en esta reflexión su máxima radicalidad. No se trata sólo de que el ser humano en su temporalidad nace y muere en la completa carencia, sino que su libertad puede ser un puente hacia una pobreza en la que se supere el deseo, el saber o el tener. Este itinerario, no obstante, no es simple ni inmediato. Requiere una apertura de la mente y del corazón. Al mismo tiempo, este camino conduciría a la unión con Dios: "en este traspaso obtengo que Dios y yo seamos una sola cosa" (Eckhart, 1983: 692). 
Fromm interpreta esta enseñanza en la polarización entre el modo del tener y el modo del ser:

En el modo de la existencia de tener, no importa qué objetos tenemos, sino toda la actitud humana. Cualquier cosa puede convertirse en objeto de la codicia las cosas que usamos en la vida diaria, las propiedades, los ritos, las buenas acciones, el conocimiento y los pensamientos. No son en sí "malos", pero se vuelven malos cuando nos aferramos a éstos, cuando se vuelven cadenas que afectan nuestra libertad e impiden nuestra realización. (Fromm, 1978: 72)

\section{CONCLUSIONES}

Una de las particularidades del pensamiento de este gran Maestro es su capacidad de trascender los límites de su época, el horizonte de preocupaciones existenciales y religiosas que modeló las ideas y las experiencias de sus contemporáneos. Esa capacidad de trascender se convierte hoy en un valor universal que permite dialogar con otras creencias, espiritualidades y religiosidades.

Eckhart en cada sermón y tratado nos muestra la maestría que tiene en la interpretación bíblica, aunque la suya sea más alegórica y simbólica ${ }^{6}$ que histórico-crítica o narratológica ${ }^{7}$. Todos sus comentaristas y traductores le reconocen una habilidad extraordinaria para estirar cada idioma hasta el límite para condensar allí su experiencia espiritual. En especial, en la lengua común en la que predicó sus sermones, Eckhart alcanza en los recursos elocutivos, argumentativos y, sobre todo, figurativos unos límites que pocas veces se han visto en la prosa religiosa y teológica, como lo señala De Brugger ${ }^{8}$. De hecho la estructura de cada uno de sus sermones se puede entender como una exégesis espiritual que busca interpelar al

$6 \quad$ Esto se puede ilustrar en cada uno de los sermones, pero también se detecta en la obra latina. "Así como la vista para poder captar todos los colores no tiene color alguno, así también el entendimiento para poder captar todos los seres no ha de tener ser alguno" (Capelletti, 1962: 12).

7 "No se puede hablar propiamente de un lenguaje teológico, sino de un pensamiento o una concepción teológica del lenguaje, cuya función connotativa comunica algo distinto, escondido, secreto y difícil de expresarse” (González Bernal, 2017: 208).

8 "Los predicadores contribuyeron decisivamente al enriquecimiento del lenguaje, tanto con la introducción de nuevas voces - cuyo contenido debía corresponder al de las palabras latinas que les servían de modelo - como con una mayor flexibilización de la prosa, hasta entonces poco elaborada, para expresar pensamientos abstractos y vincularlos fluidamente con los habituales «ejemplos» y anécdotas, tomados de la vida cotidiana. Si esto valía para la prédica corriente en alemán, cuanto más para los sermones de alto vuelo, pronunciados por predicadores empeñados en acercar sus oyentes a las cumbres místicas" (De Brugger, 1983: 22). 
creyente en lo profundo de su existencia. Estilo de pensamiento que encontraremos mucho más tarde en Kierkegaard, en Edith Stein o en los existencialistas. Con todo, lo que hace este Maestro es desmontar una a una la pretensión de saber, de querer o, más radicalmente, las certezas del tener.

Con ello, Eckhart tiene el poder de ponerse en contacto con la sensibilidad y el pensamiento de nuestra época en la que se ha radicalizado la lógica mercantil y en la que predomina un activismo que ahoga la reflexión serena y el cultivo espiritual. En sus reflexiones evidencia una profunda comprensión de lo que puede llegar a ser cada persona si reconoce su propia condición humana como ser carente, siempre en vía de transformación y necesitado de una orientación vital y, además, si se abre a la acción divina.

A esto habría que añadir la audacia que tiene Eckhart al articular la vida del creyente, su existencia en Dios, a la vida trinitaria. Normalmente los predicadores en esa época se hubieran contentado con que el común de los fieles entendiera las orientaciones morales elementales, pero Eckhart que sabe que esto es bueno y loable se permite ir más allá y pone al creyente cara a cara con su propia fe. En esto hay que reconocer que los tratados de misterio de Dios y de teología fundamental le deben mucho a Eckhart y todavía tienen mucho que aprender de él.

Dicho esto, giramos hacia el problema de la existencia humana, de su condición, de la interacción que corresponde a su naturaleza. Eckhart nos enseña el origen, trayecto y fin noble de cada ser humano, pero también nos hace caer en la cuenta que esa naturaleza se enfrenta al devenir no solo de las cosas o de las ideas, sino al devenir del propio espíritu que constantemente se ve saturado por el clima y los horizontes de cada época. Por ello, para Eckhart no basta con que el ser humano sea humano como cualquier otra especie o creatura de la Creación. Es necesario que cada ser humano atienda el llamado que Dios le hace y reciba su Don. En eso consiste el potencial transformador de la condición humana: en escuchar, recibir, aceptar. En pocas palabras, en saberse liberar de las cosas, vínculos y situaciones no esenciales.

En el pensamiento medieval y en la tradición humanista, la «condición humana» es motivo de permanente reflexión ya que tanto en la Escritura como en la misma sabiduría de cada pueblo se reflexiona desde diferentes puntos de vista sobre la realidad primigenia y constitutiva del ser humano. En el caso de Meister Eckhart y otros pensadores medievales, esa condición recibe una iluminación especial al colocarla bajo la luz de la razón natural y de la revelación divina.

En primer lugar, en el conjunto de sus reflexiones, Eckhart acentúa el valor que tiene la libertad humana, en especial cuando la persona ha culti- 
vado su voluntad, su entendimiento y su capacidad para actuar conscientemente. En otras palabras, se podría plantear que la esencia de la condición humana es la libertad.

Sin embargo, esta positividad del dato antropológico está sujeta a una tensión que debe ser resuelta existencialmente de manera original y creativa. La tensión entre la humanidad exterior sujeta al influjo negativo de la cultura, de la sociedad o incluso de ciertas prácticas familiares y la humanidad interior necesitada de cultivo y de una formación que destaque o rescate la imagen de Dios en el ser humano. La tendencia ascendente que conduce a la unión con Dios mediante el desasimiento progresivo y radical de lo que se tiene, de lo que se quiere tener y de todo aquello (personas, cosas, situaciones) que retienen al ser humano. Este camino de desasimiento se identifica en la teología neotestamentaria con la palabra kénososis y adquiere un carácter paradigmático en la persona y acción de Jesús.

Este camino ascendente pasa, sin embargo, por una afirmación del espíritu humano que realiza efectivamente su libertad en el desprendimiento, liberación o desasimiento de la codicia de posesiones o de la ambición de prestigio. En razón de la enorme valoración que da Eckhart a las posibilidades del ser humano en cuanto ser libre, capaz y pensante, la superación del apego alienante a las cosas, a los conocimientos y a los deseos pasa por un proceso de kénosis o desasimiento en el que la obediencia de la fe permite que por gracia se llegue a la unión con Dios. O en palabras de Eckhart: "cualquier cosa que el ser humano sufre por Dios y sólo por Él, Dios se la convierte en liviana y dulce" (Eckhart, 1983: 277).

En segundo lugar, la humildad de la condición humana está ligada a las condiciones de una gracia transformadora. Para Eckhart, el ser humano es criatura que, en su condición terrena, se encuentra limitado y con una clara tendencia a equivocarse; además, constantemente está asediado por las tentaciones, lo que lo hace aún más vulnerable. Sin embargo, esta misma fragilidad radical, puede llegar a ser un punto de partida para el encuentro con su creador, puesto que la cuestión no está en la labilidad, sino en la libertad que el ser humano tiene para elegir el camino del bien. En este sentido, la 'lucha contra las tentaciones' en el pensamiento de este gran maestro no se trata del control de la condición humana, sino del dominio sobre las acciones humanas. Al decir de E. Fromm, "en el sistema ético de Eckhart, la virtud suprema es el estado de actividad interior productiva, y la premisa es superar todas las formas de estar atado al ego y a la codicia" (1991: 74).

En tercer lugar, para Eckhart la actividad auténtica, transformadora se identifica con la vita contemplativa, en la que el ser humano puede descubrir realmente la potencia de su ser. Por esto, la actividad no se identifica con el activismo febril o con la producción de lucro. 
Esta actividad contemplativa conlleva una dimensión ética. Para Eckhart la persona justa no solo procura el bien, sino que reconoce en sí misma la tendencia al mal y se retrae en una inacción positiva. Incluso si una persona en total libertad elige el pecado, esta acción no elimina la posibilidad de salvación, sino que por vía negativa la confirma. El reconocimiento del pecado no niega en este sistema de pensamiento la posibilidad de que este camino no pueda conducir, en últimas, al encuentro con Dios por la vía del arrepentimiento, es decir, del re-pensar y re-plantear la acción. En otras palabras, las posibilidades de la gracia son inconmensurablemente superiores a la densidad del pecado.

En tercer lugar, algunas categorías como desasimiento vaciamiento o kénosis y como obediencia o escucha dócil de la voluntad, identifican condiciones humanas imprescindibles para la unión con Dios. La condición de desvalimiento o despojo y la primacía de la escucha sobre los otros sentidos constituyen un dato primario de la existencia humana en el momento del nacimiento que, de no ser bien cultivados se sustituyen por la ambición y por la contumacia. El cultivo del vaciamiento y de la obediencia en cuanto ejercicio del ser sobre otras posibilidades humanas, implica una primacía absoluta de lo que se recibe de Él, el Creador, frente a las cosas o las personas, o creaturas, a las que el ser humano se apega. En otras palabras, es la preeminencia del ser sobre el tener (Fromm, 1991: 16).

En cuarto lugar, la antropología que se puede rastrear en el pensamiento de Eckhart muestra una valoración realista del pecado como una realidad que supera la esfera individual de cada ser humano. Ahora bien, el maestro Eckhart llama la atención sobre la condición de debilidad del ser humano frente al pecado y sobre las vicisitudes y tribulaciones de la vida normal que le hacen aún más propenso al pecado, pero frente a las cuales también tiene la facultad del amor, de la voluntad del bien y del propio desasimiento en cuanto se alcanza una comprensión de la misma condición humana, bien sea por la unión con Dios (mística) o bien sea por la misma razón con la que el creador nos ha dotado y con la que nos acercamos a Él (ascesis).

El maestro pone en evidencia que la condición humana está expuesta permanentemente al pecado, pero, ve en el pecado una enseñanza de que el arrepentimiento profundo, intenso, lleva al hombre a reconocer el amor de Dios. De esta manera, para el maestro, la inclinación al pecado resulta de provecho al creyente, puesto que le lleva a reflexionar sobre su misma condición humana y sobre las inmensas posibilidades de hacer el bien y de alejarse del mal, porque como bien lo dice el maestro:

La inclinación al pecado no es pecado, pero querer pecar, esto sí es pecado, querer encolerizarse, esto sí es pecado. En verdad, si aquel que está bien 
encaminado tuviera el poder de desear, no se le ocurriría desear que perdiera la inclinación al pecado, pues sin ella el hombre estaría inseguro en todas las cosas y en todas sus obras y no sentiría preocupación frente a las cosas, y carecería también del honor ganado con la lucha, de la victoria y de la recompensa. (Eckhart, 1983: 72)

En últimas, para el maestro Eckhart, el ser humano si bien es imagen y semejanza de Dios, también está sujeto a la libertad. La condición humana se desarrolla en una historia que evidencia las implicaciones de su libertad. Esta condición está signada por el sufrimiento, las tribulaciones, los infortunios y las perdidas; pero también, estas situaciones, encuentran un consuelo divino, cuando la criatura en su ser y en su obrar renuncia así mismo y a su voluntad, y se abre a la acción divina. El maestro adjudica tres causas que llevan al ser humano a sufrir:

Una proviene del daño sufrido en los bienes exteriores, otra del daño hecho a sus parientes y amigos, y la tercera del daño que soporta él mismo a causa del menosprecio e infortunio, de dolores físicos y hondos pesares. (Eckhart, 1973: 9)

Así la condición humana, según el maestro, es aquella que nos acompaña en nuestra naturaleza, la que genera interrogantes $y$, a su vez, la que no cuenta con las respuestas. La condición humana, es también para el maestro, el lugar del bien moral, el cual consiste en la entrega total y absoluta a la voluntad de Dios, y al desapego de toda realidad exterior. Por lo tanto, entra también en su pensamiento teológico, la culpa y el pecado, que es fruto de la condición humana, y se da por el deseo de posesión y la pérdida de la conciencia de la interioridad divina, aun así el maestro, descubre que en el pecado, el hombre siente la angustia de la nada, y al sentir y comprender la angustia, le lleva a recogerse en su interior y a recomponerse por dentro, puesto que "el círculo espiritual no se afianza si él no reconoce el llamado de la angustia y con un acto de amor y de entrega no se libera del golpe de su pecaminosa aflicción y de sus motivos prácticos y se adhiere con un acto de voluntad a la voluntad de Dios identificándola con ésta" (Faggin, 1953: 70-71).

\section{REFERENCIAS}

Bara Bancel, S. (2015). Teología mistica alemana. Estudio comparativo del «Libro de la Verdad» de Enrique Suso y la obra del Maestro Eckhart. [Beiträge zur Geschichte der Philosophie und Theologie des Mittelalters, NF 78]. Münster: Aschendorff. 
De Brugger, I. M. (1983). Introducción. En Maestro Eckhart. Obras alemanas. Tratados y sermones. (Brugger, I. M. de, Trad., introducción y notas; pp. 9-82). Barcelona: Edhasa.

Capelletti, Á. J. (1962). Introducción. En Cuestiones parisienses. Tucumán: Universidad Nacional de Tucuman.

Davies, O. (1994). Introduction. En O. Davies (Ed.), Meister Eckhart. Selected Writings (pp. xi-xxxviii). Londres: Penguin Books.

Eckhart, M. (1983). Obras alemanas. Tratados y sermones. (Brugger, I. M. de., Trad., introducción y notas). Barcelona: Edhasa.

Eckhart, M. (2002). Vida eterna y conocimiento divino. (Grinberg, M., Selección, traducción e introducción). Buenos Aires: Devas.

Eckhart, M. (2009). Commento al vangelo di Giovanni. (Vannini, M., Introduzione, traduzione, note e indici). Roma: Città Nuova.

Eckhart, M. (2014). Le 64 prediche sul tempo litúrgico. (Sturlese, L., Introduzione, traduzione, note e apparati). Milán: Bompiani.

Faggin, G. (1953). Meister Eckhart y la mistica alemana medieval. Buenos Aires: Sudamérica.

Fromm, E. (1991). Del tener al ser. Caminos y extravios de la conciencia. Barcelona: Paidós.

Fromm, E. (1978). Tener o ser. México, D. F.: Fondo de Cultura Económica.

Gadamer, H. G. (1993). Verdady Método. Salamanca: Sígueme.

González Bernal, E. (2017). Misticas medievales. El rostro femenino de la teología. Bogotá: Pontificia Universidad Javeriana.

Grinberg, M. (2002). Introducción. La chispa de Dios. En Maestro Eckhart. Vida eterna y conocimiento divino. Buenos Aires: Deva's.

Haas, A. M. (2002). Maestro Eckhart. Figura normativa para la vida espiritual. Barcelona: Herder.

Lavaud, L. (2012). Humilité et pauvereté: deux figures de l'unité entre l'âme et Dieu. En J. Casteigt (Ed.), Maître Eckhart (pp. 123-144). Paris: Les Éditions du Cerf.

Sauer, E. F. (1973). Filósofos alemanes. De Eckhart a Heidegger. (Presentación crítica y juicios sobre sus filosofías). México, D. F.: Fondo de Cultura Económica.

Soto Posada, G. (2007). Filosofía medieval. Bogotá: San Pablo.

Sturlese, L. (2014). Le prediche tedesche di Meister Eckhart. En Meister Eckhart. Le 64 prediche sul tempo litúrgico. (Sturlese, L., Introduzione, traduzione, note e apparati; pp. VII-LXXXVII). Milán: Bompiani.

Vannier, M. A. (2012). L'anthropologie d'Eckhart. En J. Casteigt (Ed.), Maître Eckhart (pp. 145-162). Paris: Les Éditions du Cerf.

Vannini, M. (2009). Introduzione. En M. Vannini (Ed.), Commento al Vangelo di Giovanni (pp. 5-41). Roma: Città Nuova.

Sumario: Introducción; 1. Itinerario en el pensamiento eckhartiano; 2. La nobleza humana; 3. Quid prodest, la ganancia espiritual; 4. El conocimiento es el clave; 5. La condición adoptada y enaltecida; 6. Querer, saber y tener; Conclusiones; Referencias. 